\title{
Plastics floatability: effect of saponin and sodium lignosulfonate as wetting agents
}

\author{
Fernando Pita ${ }^{*}$ (1) and Ana Castilho ${ }^{1}$ \\ ${ }^{1}$ Centro de Geociências - CGEO, Departamento de Ciências da Terra - DCT, Faculdade de Ciências e \\ Tecnologia - FCTUC, Universidade de Coimbra - UC, Coimbra, Portugal \\ *fpita@ci.uc.pt
}

\begin{abstract}
Froth flotation is the most common process in mineral processing. For the separation of plastic mixtures by flotation, the use of appropriate wetting agents is mandatory. The floatability of six post-consumer plastics was studied at different concentrations of the wetting agents, saponin and sodium lignosulfonate. Also, the influence of size and shape of the particles were analyzed. Contact angle and floatability of the six plastics decreased with increasing wetting agents concentration. The order of floatability is similar to the order of the contact angles values. However, the influence of the wetting agents in the plastics floatability is more pronounced than in the contact angle. Floatability decreased with the increase of particle density, particle size and spherical shape. For fine particles floatability is fundamentally conditioned by the contact angle, while for coarse particles floatability is fundamentally conditioned by the particles weight.
\end{abstract}

Keywords: flotation, particle size, plastic, wetting agent.

How to cite: Pita, F., \& Castilho, A. (2019). Plastics floatability: effect of saponin and sodium lignosulfonate as wetting agents. Polímeros: Ciência e Tecnologia, 29(3), e2019035. https://doi.org/10.1590/0104-1428.01419

\section{Introduction}

Plastics have become widely used materials because of their advantages, such as cheapness, durability, lightness, and hygiene. Global production of plastics has been continuously rising, gradually replacing materials like glass and metal. In the last decade, the world production of plastics has been growing around $3.5 \%$ per year, increasing from 230 million tonnes in 2005 to 348 million tonnes in 2017, with an European production of 64.4 million tonnes (18.5\% of the world plastic production) $)^{[1]}$. In 2017, Europe demand for plastic materials was 51.2 million tonnes, but about 39\% of the demand is concentrated in two countries: Germany and Italy ${ }^{[1]}$. To take full advantage of the benefits of plastics, their products require a proper recovery and management when they reach the end of their service life. Recycling is the preferred option for plastics waste. In Europe, in 2016, $31.1 \%$ of post-consumer plastic was recycled and $41.6 \%$ was recovered through energy recovery processes, being the landfill disposal the main form of plastics disposal $(27.3 \%)^{[1]}$. In the last decade, recycling has increased by $79 \%$, incineration has increased by $61 \%$ and landfilling has decreased by $43 \%$. It should be noted that, in some countries, such as Austria and the Netherlands, less than $1 \%$ of plastics are deposited in landfills, while in other countries, like Malta and Greece, about $80 \%$ of plastics are deposited in landfills.

Plastics recycling require the separation from other constituents and also the separation of plastic mixtures into individual plastics in order to achieve a good recycled plastic quality. Over the recent years, some separation technologies developed in mineral processing engineering have been applied in the separation of plastic mixtures into their individual components. One of them is the froth flotation method.
Flotation is the most common concentration process used by the mineral industry, allowing the separation of hydrophobic material from hydrophilic one. In a mixture of hydrophobic and hydrophilic particles suspended in water, with air bubbled through the suspension, the hydrophobic particles attach to the air bubbles and by buoyancy are transported from the suspension to the froth zone. The hydrophilic particles do not attach to air bubbles, thus remaining in the pulp. The use of flotation for plastics separation is particularly challenging because, unlike most minerals, most plastics are hydrophobic in their natural state. Thus, in order to separate plastic mixtures by froth flotation, one or more plastic type must become hydrophilic by the addition of selective wetting agents, while the others are maintained hydrophobic ${ }^{[2-5]}$. Several wetting agents of plastics have been tested for the selective flotation of plastic mixtures. Methyl cellulose, polyvinyl alcohol, polyethylene glycol, gelatin, tannic acid, saponin, terpineol, triton X-100, calcium lignosulfonate and sodium lignosulfonate have been used as wetting agents by several authors ${ }^{[6-17]}$. Plastic flotation is controlled not only by the hydrophobicity, but also by the shape and size of the plastic particles ${ }^{[18-22]}$.

This work aimed to study the influence of saponin and sodium lignosulfonate on the floatability of six plastics, and also, to compare it with the effect of tannic acid ${ }^{[22]}$. Moreover, it tried to establish the ideal concentrations of these two wetting agents to separate plastic mixtures and evaluate the relations of the floatability of plastics with contact angles and gravity factors, such as particle density, particle shape and particle size. 


\section{Experimental}

\subsection{Materials and methods}

This work used six types of post-consumer plastic: Polystyrene (PS, black), Polymethyl methacrylate (PMMA, white), Polyethylene Terephthalate (PET-S, blue), Polyethylene Terephthalate (PET-D, transparent), Polyvinyl Chloride (PVC-M, light green) and Polyvinyl Chloride (PVC-D, gray) (Figure 1). The density of these plastics, measured by an Ultra Pycnometer (AccuPyc 1330), are as follows: PS: $1.047 \mathrm{~g} / \mathrm{cm}^{3}$; PMMA: $1.204 \mathrm{~g} / \mathrm{cm}^{3}$; PET-S: $1.372 \mathrm{~g} / \mathrm{cm}^{3}$; PET-D: $1.364 \mathrm{~g} / \mathrm{cm}^{3}$; PVC-M: $1.326 \mathrm{~g} / \mathrm{cm}^{3}$ and PVC-D: $1.209 \mathrm{~g} / \mathrm{cm}^{3}$. To study the influence of the particle size, the material was classified by sieving in five size fractions: $+1-1.4 \mathrm{~mm},+1.4-2 \mathrm{~mm},+2-2.8 \mathrm{~mm},+2.8-4 \mathrm{~mm}$ and $+4-5.6 \mathrm{~mm}$. The shape factor, defined by the ratio between the thickness $\left(\mathrm{D}_{\min }\right)$ and length $\left(\mathrm{D}_{\max }\right)$, of the six plastics versus size fractions was already assessed ${ }^{[2]}$. PMMA, PS and PVC-D particles presented more spherical shapes, while PET-D particles showed lamellar shapes. Particle shape factor proportionally decreased with particle size in PET-D, PET-S and PVC-M, whereas in the other three plastics, particle shape factor increased with particle size.

Wetting agents used in the flotation experiments were saponin (84510 Sigma Aldrich) and sodium lignosulfonate (471038 Sigma Aldrich). Methyl isobutyl carbinol (MIBC) (109916 Sigma Aldrich) was used as frothing reagent.

\subsection{Contact angle measurements}

The interaction between particles and air bubbles is a key element to effectively recover valuable minerals via flotation process. The easiest way to determine the hydrophobicity of a substance is to measure the contact angle, that is, the angle formed by a water droplet in contact with a solid surface. There is a positive correlation between the hydrophobicity and the floatability, i.e., the flotation recovery increases with the increase of the contact angle. Contact angles were measured in the Data Physics Instruments OCA20 equipment, using the sessile drop method. A water drop was placed onto the surface of plastic particles (before and after their treatment with the wetting agents) and the different contact angles were measured. This process was repeated seven times for each plastic and the average value was considered to be the contact angle of the plastic.

\subsection{Flotation experiments}

Flotation experiments were performed in a Denver cell with a capacity of $3 \mathrm{dm}^{3}$. Each test used $40 \mathrm{~g}$ of plastics and was conditioned with different concentrations of wetting agents (saponin and sodium lignosulfonate) for about 5 minutes and later with the frother (MIBC) for about 2 minutes before the flotation, at the constant concentration of $30 \times 10^{-3} \mathrm{~g} / \mathrm{L}$ in all experiments. After conditioning, floated product was collected over 6 minutes. Both the floated and the sunk (non-floated) were dried, screened and weighed. Flotation tests were carried out previously with one-component plastic samples at different wetting agents concentrations. Then, flotation separation of plastic mixtures was done using bi-component mixtures, with each plastic type contributing with $20 \mathrm{~g}$. The effectiveness of the flotation tests was evaluated by the separation efficiency, defined by Schulz $Z^{[23]}$. In the separation tests of the plastic mixtures, the plastic types presented in floated and sunk were separated from each other by manual sorting, since the various types of plastics have different colour and shape. Experiments were done three times under similar operating conditions.
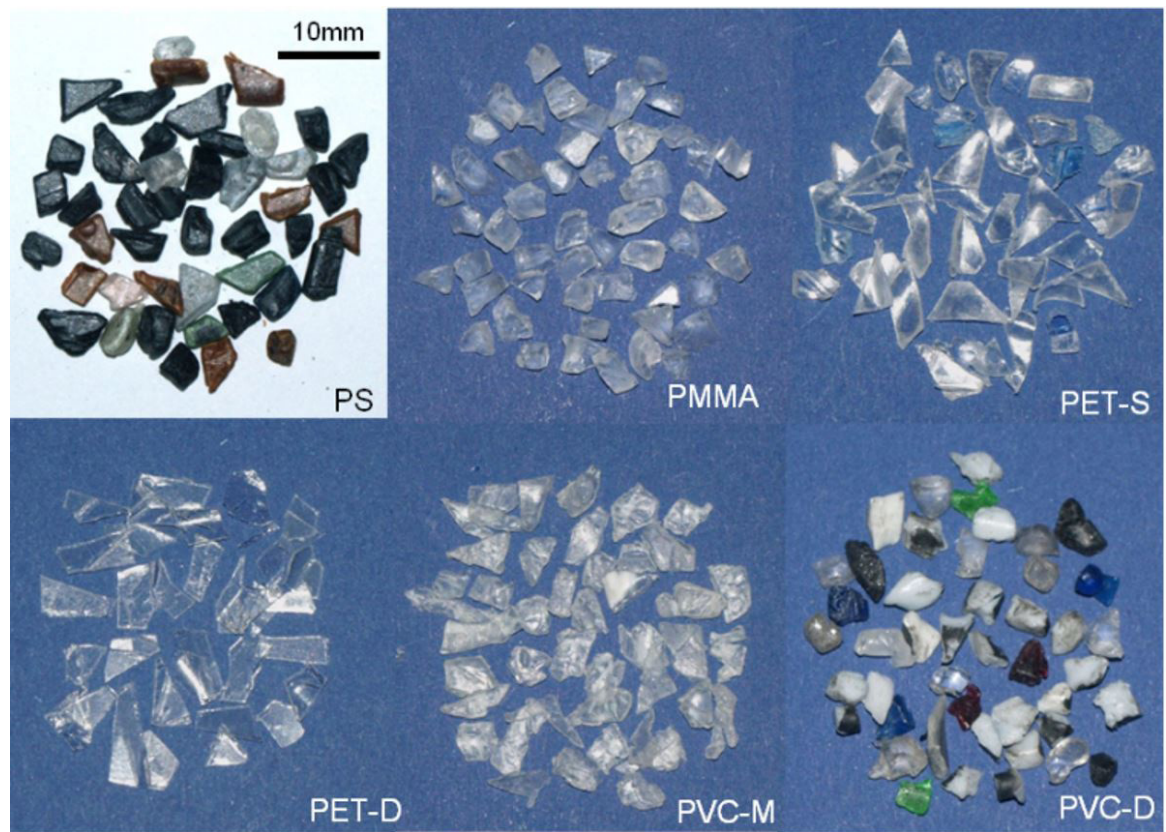

Figure 1. Original pictures of six plastics. 


\section{Results and Discussion}

\subsection{Effect of the wetting agents concentration on the contact angle of plastics}

Contact angle of the plastics decreases with increasing wetting agents concentration (Figure 2). In the absence of wetting agent, all plastics have large contact angle, with PS having the largest contact angle $\left(97^{\circ}\right)$ and PET-D the lowest $\left(73^{\circ}\right)$. The contact angles measured of the six plastics are in agreement with previous studies ${ }^{[2,6,24-27]}$.

The contact angle of the six plastics decreases with increasing saponin concentration (Figure 2a). The contact angle of PVC-M is slightly smaller than that of the other five plastics. The decrease was stronger for concentrations of saponin below $10 \mathrm{mg} / \mathrm{L}$ and was more pronounced for PS, PVC-M and PVC-D plastics. The effect of saponin on the contact angle of PS and PVC is slightly different from what was observed by $\mathrm{Ma}^{[25]}$.

The contact angle of the six plastics also decreases with increasing sodium lignosulfonate concentration (Figure 2b). The reduction of the contact angle was more pronounced for PS, PVC-M and PVC-D plastics. The effect of sodium lignosulfonate on the contact angle of PS is similar from what was observed by $\mathrm{Ma}^{[25]}$, but is different from what was observed by Wang et al. ${ }^{[28]}$. The effect of sodium lignosulfonate on the contact angle of PET follows what was observed by Florido and Torem ${ }^{[29]}$. The effect of sodium lignosulfonate on the PVCs contact angle is similar from what was observed by Shibata et al. ${ }^{[6]}, \mathrm{Ma}^{[25]}$ and Wang et al. ${ }^{[28]}$, but is different from what was observed by Pascoe and $\mathrm{Hou}^{[18]}$.

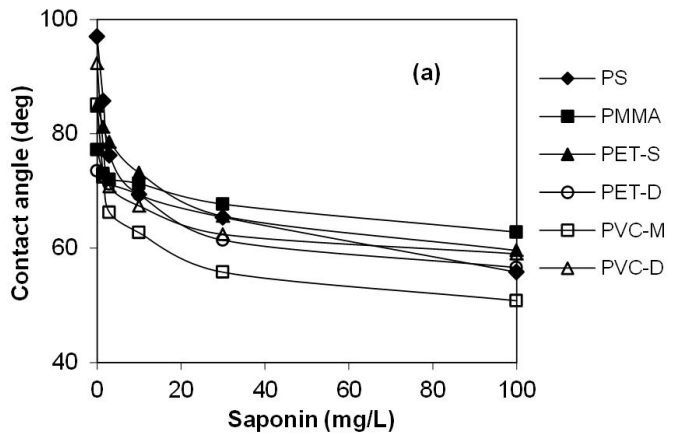

Pita and Castilho ${ }^{[22]}$ verified that the decrease of contact angles of these six plastics occurs for small concentrations of tannic acid. A concentration of $5 \mathrm{mg} / \mathrm{L}$ of tannic acid caused similar decreases of the contact angle to those obtained for concentrations of $100 \mathrm{mg} / \mathrm{L}$ of saponin and $300 \mathrm{mg} / \mathrm{L}$ of sodium lignosulfonate.

\subsection{Effect of the wetting agent concentration on the floatability of plastics}

The recovery of the six plastics in the floated decreases with an increase of the two wetting agents concentration (saponin and sodium lignosulfonate) (Figure 3). It is verified that all the studied plastics are naturally floatable, because in the absence of wetting agents the flotation recovery is about $100 \%$. The same behaviour was observed in other studies $^{[6,19,24,25,27-29]}$. Even PET-D and PMMA, with contact angle below $80^{\circ}$ in the absence of a wetting agent, both naturally float. Similarly, other studies ${ }^{[25,27,28]}$ using PS, PMMA, PET and PVC, found that these plastics with contact angles of about $75^{\circ}$, also float naturally.

Pita and Castilho ${ }^{[22]}$ verified that depression of these six plastics occurs in smaller concentrations of tannic acid. The wetting ability order of these wetting agents for these six plastics is tannic acid $>$ saponin $>$ sodium lignosulfonate. Analogously, in the flotation of PS, PET and PVC, Shen et al..$^{[2]}$, Wang et al. ${ }^{[13]}$ and Wang et al ${ }^{[28]}$ found that the depressing effect of tannic acid is stronger than sodium lignosulfonate.

In the presence of saponin, PVC-M is the plastic with lower floatability (Figure 3a). The lower floatability of PVC-M can be justified by its lower contact angle. However, in spite

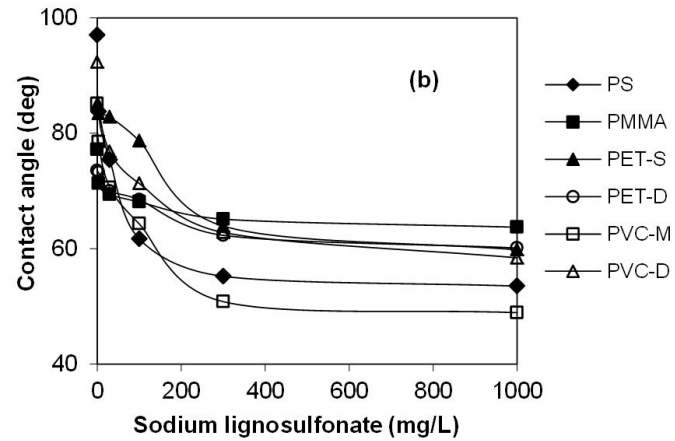

Figure 2. Contact angle of six plastics versus saponin (a) and sodium lignosulfonate (b) concentration (with standard errors less than 1.67).
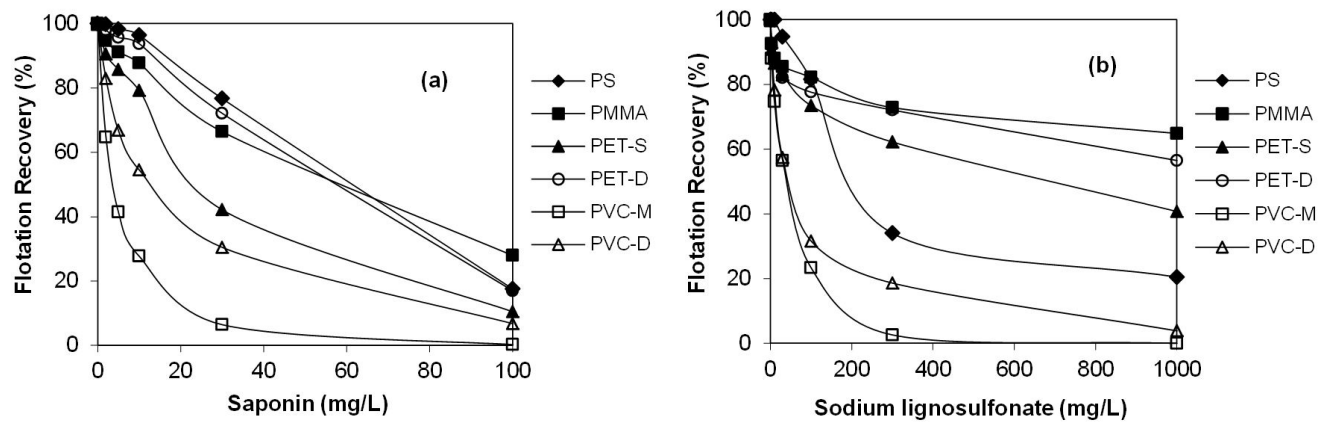

Figure 3. Floatability of six plastics versus saponin (a) and sodium lignosulfonate (b) concentration (with standard errors less than 1.74) (MIBC: $\left.30 \times 10^{-3} \mathrm{~g} / \mathrm{L}\right)$. 
of PS having one of the smallest contact angles (Figure 2a), it does not present low recoveries, perhaps explained by its low density. Also, PET-D with one of the smallest contact angles (Figure 2a), have not had small recoveries, justified by its lamellar shape. The largest difference in floatability between PVC-M and the other plastics was obtained for a concentration of saponin between $10 \mathrm{mg} / \mathrm{L}$ and $30 \mathrm{mg} / \mathrm{L}$.

The depression of plastics with sodium lignosulfonate can only be achieved with high concentrations (Figure 3b). PVC-M and PVC-D are the plastics with lower floatability. PMMA and PET-D plastics present similar behaviour and high floatability for high concentrations of sodium lignosulfonate. The low floatability of PVC-M can be justified by its lower contact angle. Better floatability of PS could be justified by its low density of this plastic. On the other hand, although PET-S has the greatest contact angle, it does not present the greatest recovery, perhaps explained by its greater density. PVC-M is depressed selectively from the other plastics. Maximum difference between the recovery of PVC-M and the other plastics is obtained with concentrations of sodium lignosulfonate between 100 and $300 \mathrm{mg} / \mathrm{L}$.

For the two wetting agents, the difference between the floatability of the plastics is much greater than the difference between the respective contact angles.

Pita and Castilho ${ }^{[22]}$ verified that in the presence of tannic acid, PS is the plastic with higher floatability, and the other five plastics show similar variation of the floatability, being depressed at very low tannic acid concentration. So, the largest difference of the floatability between PS and the other five plastics is obtained using tannic acid ${ }^{[22]}$, but the largest difference of the floatability between the other five plastics is obtained using saponin or sodium lignosulfonate.

\subsection{Effect of the particle size on the floatability of plastics}

Particle size is an important parameter in the flotation process. For all size fractions, the floatability of the six plastics decreases with the increase of the two wetting agents concentration (Figure 4-5). In the presence of
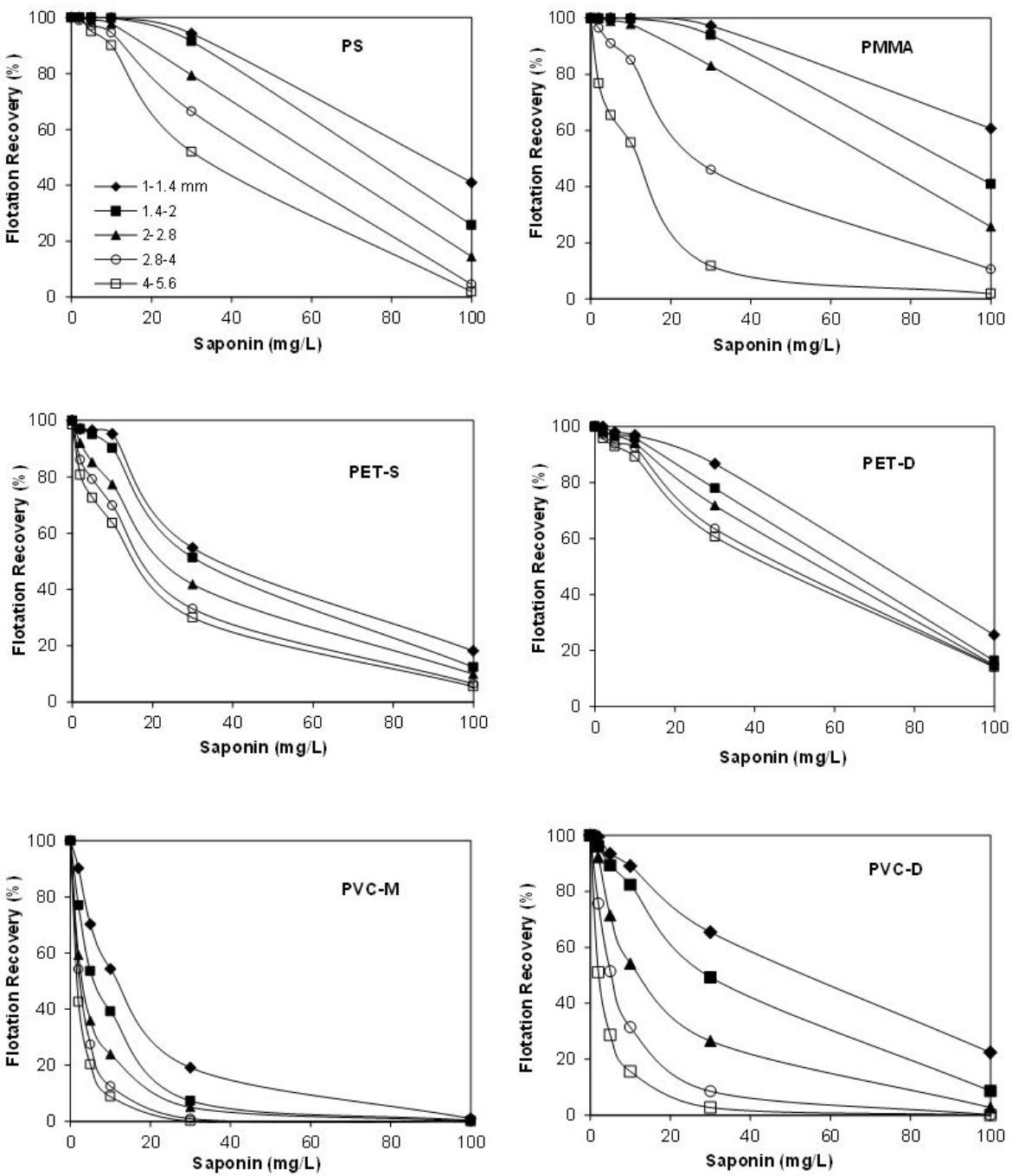

Figure 4. Influence of saponin concentration and particle size on the floatability of six plastics (with standard errors less than 1.70) (MIBC: $30 \times 10^{-3} \mathrm{~g} / \mathrm{L}$ ). 

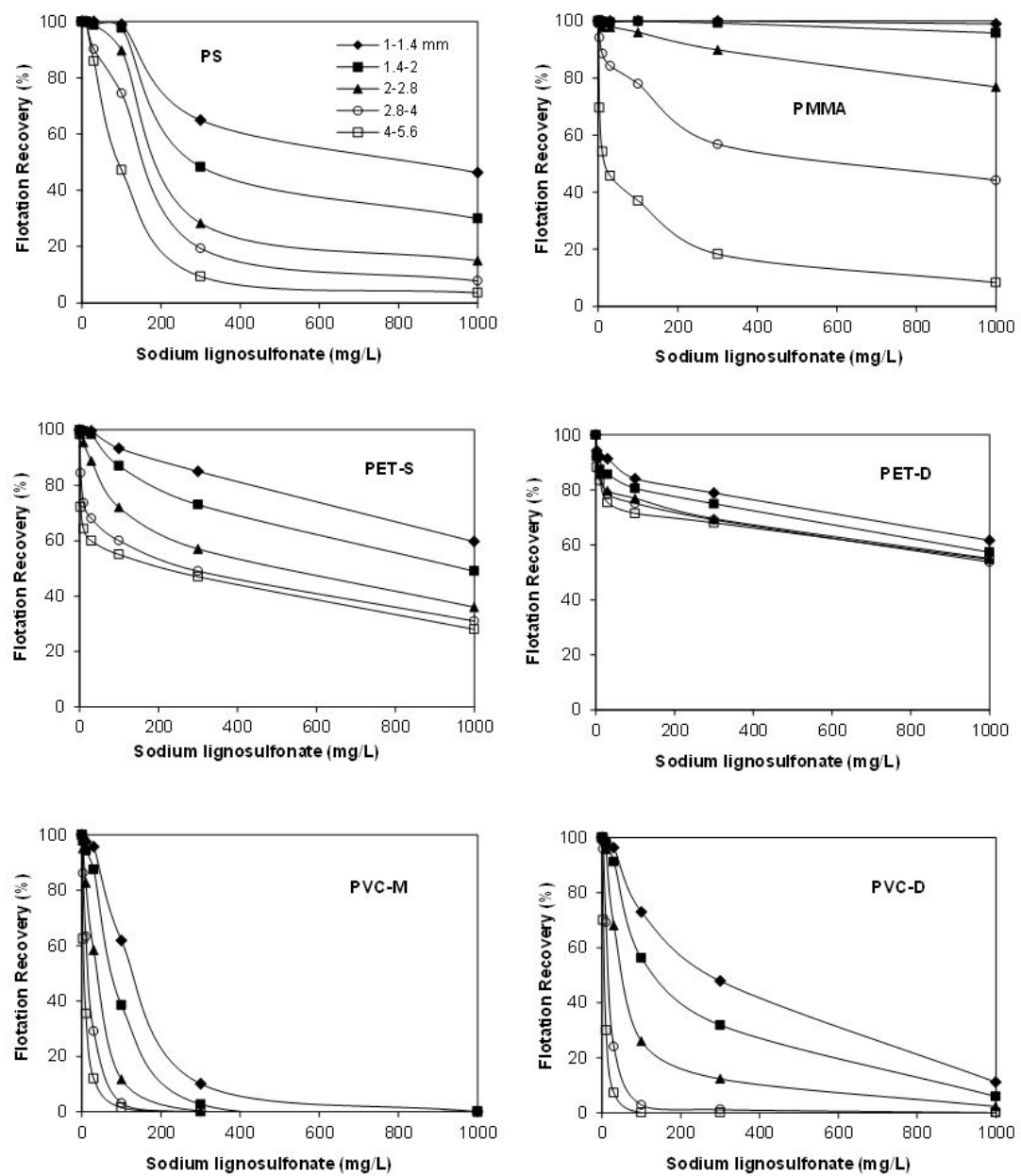

Figure 5. Influence of sodium lignosulfonate concentration and particle size on the floatability of six plastics (with standard errors less than 1.62) (MIBC: $30 \times 10^{-3} \mathrm{~g} / \mathrm{L}$ ).

saponin or sodium lignosulfonate, for the three finer size fractions, PMMA presents the greatest floatability, and for the two larger size fractions, PET-D presents the greatest floatability. PVC-M presents the smallest floatability for all size fractions.

For the six plastics and for the two wetting agents, the flotation recovery decreased with increasing particles size. It was also observed that plastics with a more lamellar shape, such as PET-D, show less influence of the particles size in the floatability. On the other hand, the floatability of plastics with a more regular shape (PMMA and PVC-D) is more influenced by the particles size. The decrease of the floatability of plastics with the increasing particles size, mainly plastics with a regular shape, is a consequence of the greater weight of the coarse particles, which require a larger number of air bubble carriers in order to float, that is, to form particle-bubbles aggregates with a density lower than the density of the water.

Considering the plastic particles weight, the density of the particle-bubbles aggregates of the six plastics has the order followed in Table 1. Also, in Table 1 it is presented the order of contact angle of the six plastics and the order of floatability in the presence of the saponin, sodium lignosulfonate and tannic acid ${ }^{[22]}$ for the finer and coarser fractions. In the presence of saponin, for the finer fraction, PVC-M has the lowest floatability as consequence of its lower contact angle. On the contrary, PMMA has the greatest floatability as consequence of its greater contact angle. Since for the finer fraction the particles are lightweight, the floatability is mainly affected by hydrophobicity. For the coarser fraction, the greatest floatability of PET-D can result from the lower weight of the particle-bubbles aggregates, therefore, they require the attachment of less air bubbles to float, whereas the lowest floatability of PVC-M can result from the greatest weight of the particle-bubbles aggregates or the lowest contact angle. For the coarser fraction, the low floatability of PVC-D and PMMA can result from the high density of the particle-bubbles aggregates.

In the presence of sodium lignosulfonate, for the finer fraction, PVC-M has once again the lowest floatability as consequence of its lower contact angle; PMMA has the greatest floatability as consequence of its greater contact angle. For the coarser fraction, the greatest floatability of PET-D can result from the lower weight of the PET-D 
Table 1. Ranking of the six plastics in the finer and coarser fractions: density of particle-bubbles aggregates; contact angle and floatability in the presence of the three wetting agents.

\begin{tabular}{cc}
\hline Particle-bubble aggregates density & Ascendant order of the six plastic \\
\hline $1 / 1.4 \mathrm{~mm}$ & PS $<$ PET-D $\approx$ PMMA $<$ PVC-D $<$ PET-S $\approx$ PVC-M \\
$4 / 5.6 \mathrm{~mm}$ & PS $<$ PET-D $<$ PET-S $<$ PVC-M $\approx$ PMMA $\approx$ PVC-D \\
Saponin $(10 \mathrm{mg} / \mathrm{L})$ & \\
Contact angle & PVC-M $<$ PET-D $<$ PVC-D $<$ PS $\approx$ PET-S $<$ PMMA \\
Experimental floatability & \\
$1 / 1.4 \mathrm{~mm}$ & PVC-M $<$ PET-S $<$ PVC-D $<$ PET-D $<$ PS $<$ PMMA \\
$4 / 5.6 \mathrm{~mm}$ & PVC-M $\approx$ PVC-D $<$ PMMA $<$ PET-S $<$ PS $<$ PET-D \\
& \\
Sodium lignosulfonate $(300 \mathrm{mg} / \mathrm{L})$ & PVC-M $<$ PS $<$ PET-D $<$ PET-S $<$ PVC-D $<$ PMMA \\
Contact angle & PVC-M $<$ PVC-D $<$ PS $<$ PET-D $<$ PET-S $<$ PMMA \\
Experimental floatability & PVC-M $\approx$ PVC-D $<$ PS $<$ PMMA $<$ PET-S $<$ PET-D \\
$1 / 1.4 \mathrm{~mm}$ & \\
$4 / 5.6 \mathrm{~mm}$ & \\
Tannic acid $(3 \mathrm{mg} / \mathrm{L})^{[22]}$ & PET-D $<$ PVC-M $<$ PMMA $<$ PVC-D $<$ PET-S $<$ PS \\
Contact angle & PET-D $<$ PVC-M $<$ PET-S $<$ PVC-D $<$ PMMA $<$ PS \\
Experimental floatability & PVC-M $\approx$ PMMA $<$ PVC-D $\approx$ PET-S $<$ PET-D $<$ PS \\
$1 / 1.4 \mathrm{~mm}$ & \\
$4 / 5.6 \mathrm{~mm}$ &
\end{tabular}

particles, whereas the low floatability of PVC-D can result from the higher weight of the PVC-D.

In the presence of tannic acid, for the finer fraction, PET-D has the lowest floatability as consequence of its lower contact angle ${ }^{[22]}$. For the coarser fraction, the lowest floatability of PVC-M and PMMA can result from the highest weight of the particles, whereas the greatest floatability of PS can result from the greater contact angle or from the lower density of the particle-bubble aggregates.

It is verified that the plastics floatability depends on their hydrophobicity (contact angle) and particle weight (size, shape and density). Plastics with larger contact angle, lower density, smaller size and lamellar shape, have achieved higher floatability. In the presence of the three agents and for finer particles, the floatability order is similar to the contact angle order, and for the coarser fraction, the floatability order is similar to the density order. For the finer fraction, the influence of hydrophobicity (contact angle) is stronger, whereas for the coarser fraction, the influence of particle weight is stronger.

\subsection{Separation of bi-component mixtures of plastics}

In the presence of saponin or sodium lignosulfonate, PVC-M has lower floatability than the others plastics. So, in the presence of saponin or sodium lignosulfonate, further flotation tests were developed using bi-component plastic mixtures of PVC-M and other plastic in equal proportions, to obtain a selective separation of PVC-M. For saponin flotation tests, the concentration of $10 \mathrm{mg} / \mathrm{L}$ was used, because it led to the largest difference in floatability between PVC-M and the other plastics. Sodium lignosulfonate concentration of $100 \mathrm{mg} / \mathrm{L}$ led to the best separation for PVC-M/PS, whereas concentration of $300 \mathrm{mg} / \mathrm{L}$ led to the best separation for PVC-M//PMMA, PVC-M/PET-S and PVC-M/PET-D.
Saponin led to a better separation of the PVC-M/PS mixture than sodium lignosulfonate (Table 2 and 3). However, sodium lignosulfonate led to a better separation of PVC-M/PMMA, PVC-M/PET-S and PVC-M/PET-D than saponin. The best results were obtained in the PVC-M/PMMA and PVC-M/PET-D mixtures separation with sodium lignosulfonate, having the highest separation efficiency (near 70\%) (Table 3).

The worst results were obtained in the PVC-M/PET-S mixture with saponin, having the lowest separation efficiency (53.2\%). The separation efficiency of PVC-M/PS mixture with saponin and sodium lignosulfonate is worse than that observed by Pita and Castilho ${ }^{[22]}$ who used tannic acid and verified a separation efficiency of PVC-M/PS mixture in the presence of tannic acid of $94.5 \%$.

The influence of the particle size in the separation of PVC-M and other plastics with saponin and sodium lignosulfonate was also analyzed (Table 4 and 5). In the presence of saponin, the separation of the four mixtures presented the worst results for the finer particles. However, in the presence of sodium lignosulfonate, PVC-M/PMMA and PVC-M/PET-S mixtures presented the worst results for the coarser particles.

The PVC-M/PMMA mixture in the presence of sodium lignosulfonate was the one that led to the best results (Table 5). For the $+1.4-2 \mathrm{~mm}$ fraction, the separation efficiency was maximum $(96.5 \%)$, where the PVC-M recovery in the non-floated was $96.9 \%$ with a grade of $99.6 \%$ and the PMMA recovery in the floated was $99.6 \%$ with a grade of $97.0 \%$.

In the presence of saponin, for the finer fraction, the separation efficiency order of the four plastic mixtures (PVC-M/PET-S < PVC-M/PET-D $\approx$ PVC-M/PMMA $\approx \mathrm{PVC}-\mathrm{M} / \mathrm{PS})$ is similar to the contact angle order (PVC-M $<$ PET-D $<$ PS $\approx$ PET-S $<$ PMMA). For the coarser fraction, the separation efficiency order of the five plastic 
Table 2. Results of the flotation tests on the mixtures of PVC-M with PS, PMMA, PET-S and PET-D in the presence of saponin (average and standard error of three samples).

\begin{tabular}{|c|c|c|c|c|c|c|}
\hline \multirow{2}{*}{ Plastic Mixtures } & \multirow{2}{*}{ Products } & \multicolumn{2}{|c|}{ Recovery (\%) } & \multicolumn{2}{|c|}{ Grade (\%) } & \multirow{2}{*}{$\begin{array}{c}\text { Separation Efficiency } \\
(\mathrm{SE})(\%)\end{array}$} \\
\hline & & PVC-M & OP* & PVC-M & OP* & \\
\hline \multirow[t]{2}{*}{ PVC-M/PS } & Non-Floated & $72.8(1.15)$ & $3.3(0.45)$ & 95.7 & 4.3 & 69.5 \\
\hline & Floated & 27.2 & 96.7 & 21.9 & 78.1 & \\
\hline \multirow[t]{2}{*}{ PVC-M/PMMA } & Non-Floated & $72.1(1.07)$ & $11.5(0.78)$ & 86.2 & 13.8 & 60.6 \\
\hline & Floated & 27.9 & 88.56 & 24.0 & 76.0 & \\
\hline \multirow[t]{2}{*}{ PVC-M/PET-S } & Non-Floated & $71.7(0.88)$ & $18.5(0.95)$ & 79.5 & 20.5 & 53.2 \\
\hline & Floated & 28.3 & 81.5 & 25.8 & 74.2 & \\
\hline \multirow[t]{2}{*}{ PVC-M/PET-D } & Non-Floated & $71.9(0.97)$ & $6.0(0.64)$ & 92.23 & 7.7 & 65.9 \\
\hline & Floated & 28.1 & 94.0 & 23.0 & 77.0 & \\
\hline
\end{tabular}

OP* denotes the other plastics, namely PS, PMMA, PET-S or PET-D.

Table 3. Results of the flotation tests on the mixtures of PVC-M with PS, PMMA, PET-S and PET-D in the presence of sodium lignosulfonate (average and standard error of three samples).

\begin{tabular}{|c|c|c|c|c|c|c|}
\hline \multirow{2}{*}{ Plastic Mixtures } & \multirow{2}{*}{ Products } & \multicolumn{2}{|c|}{ Recovery (\%) } & \multicolumn{2}{|c|}{ Grade (\%) } & \multirow{2}{*}{$\frac{\text { Separation Efficiency }}{(\mathrm{SE})(\%)}$} \\
\hline & & PVC-M & OP* & PVC-M & OP* & \\
\hline \multirow[t]{2}{*}{ PVC-M/PS } & Non-Floated & $77.4(1.21)$ & $18.3(1.02)$ & 80.9 & 19.1 & 59.1 \\
\hline & Floated & 22.7 & 81.7 & 21.7 & 78.3 & \\
\hline \multirow[t]{2}{*}{ PVC-M/PMMA } & Non-Floated & $97.1(1.32)$ & $25.7(1.26)$ & 79.1 & 20.9 & 71.4 \\
\hline & Floated & 2.9 & 74.3 & 3.7 & 96.3 & \\
\hline \multirow[t]{2}{*}{ PVC-M/PET-S } & Non-Floated & $97.6(0.98)$ & $37.3(1.12)$ & 72.4 & 27.7 & 60.3 \\
\hline & Floated & 2.4 & 62.7 & 3.7 & 96.3 & \\
\hline \multirow[t]{2}{*}{ PVC-M/PET-D } & Non-Floated & $97.0(1.07)$ & $27.3(1.15)$ & 78.0 & 22.0 & 69.7 \\
\hline & Floated & 3.1 & 72.7 & 4.0 & 96.07 & \\
\hline
\end{tabular}

OP* denotes the other plastics, namely PS, PMMA, PET-S or PET-D.

Table 4. Influence of the particle size in the recovery and grade of the non-floated (concentrated of PVC-M) and floated products, in the separation of bi-component mixtures in the presence of saponin.

\begin{tabular}{|c|c|c|c|c|c|c|}
\hline & \multirow{3}{*}{$\begin{array}{l}\text { Size fraction } \\
(\mathrm{mm})\end{array}$} & \multicolumn{2}{|c|}{ Non-Floated } & \multicolumn{2}{|c|}{ Floated } & \multirow{2}{*}{$\begin{array}{c}\text { Separation } \\
\text { efficiency }\end{array}$} \\
\hline & & PVC-M & PVC-M & PS & PS & \\
\hline & & Recovery (\%) & Grade (\%) & Recovery (\%) & Grade (\%) & (SE) (\%) \\
\hline \multirow[t]{7}{*}{ PVC-M/PS } & $+1-1.4$ & 46.4 & 100.0 & 100.0 & 65.1 & 46.4 \\
\hline & $+1.4-2$ & 61.9 & 100.0 & 100.0 & 72.4 & 61.9 \\
\hline & $+2-/ 2.8$ & 77.5 & 96.7 & 97.3 & 81.2 & 74.8 \\
\hline & $+2.8-4$ & 86.6 & 94.8 & 95.3 & 87.6 & 81.8 \\
\hline & $+4-5.6$ & 91.9 & 91.0 & 90.9 & 91.8 & 82.8 \\
\hline & & PVC-M & PVC-M & PMMA & PMMA & SE (\%) \\
\hline & & Recovery (\%) & Grade (\%) & Recovery (\%) & Grade (\%) & \\
\hline \multirow[t]{7}{*}{ PVC-M/PMMA } & $+1-1.4$ & 45.6 & 100.0 & 100.0 & 64.8 & 45.6 \\
\hline & $+1.4-2$ & 63.5 & 99.2 & 99.5 & 73.2 & 63.0 \\
\hline & $+2-/ 2.8$ & 75.2 & 97.0 & 97.7 & 79.7 & 72.9 \\
\hline & $+2.8-4$ & 85.9 & 86.5 & 86.5 & 86.0 & 72.5 \\
\hline & $+4-5.6$ & 90.3 & 68.6 & 58.6 & 85.8 & 48.9 \\
\hline & & PVC-M & PVC-M & PET-S & PET-S & SE (\%) \\
\hline & & Recovery (\%) & Grade (\%) & Recovery (\%) & Grade (\%) & \\
\hline \multirow[t]{7}{*}{ PVC-M/PET-S } & $+1-1.4$ & 44.4 & 90.8 & 95.5 & 63.2 & 39.9 \\
\hline & $+1.4-2$ & 59.8 & 87.9 & 91.7 & 69.5 & 51.5 \\
\hline & $+2-/ 2.8$ & 76.7 & 78.9 & 79.4 & 77.3 & 56.1 \\
\hline & $+2.8-4$ & 86.6 & 76.0 & 72.6 & 84.4 & 59.2 \\
\hline & $+4-5.6$ & 91.2 & 74.1 & 68.1 & 88.5 & 59.3 \\
\hline & & PVC-M & PVC-M & PET-D & PET-D & SE (\%) \\
\hline & & Recovery (\%) & Grade (\%) & Recovery (\%) & Grade (\%) & \\
\hline \multirow[t]{5}{*}{ PVC-M/PET-D } & $+1-1.4$ & 47.2 & 96.4 & 98.2 & 65.0 & 45.4 \\
\hline & $+1.4-2$ & 61.0 & 94.9 & 96.7 & 71.3 & 57.7 \\
\hline & $+2-/ 2.8$ & 74.4 & 92.9 & 94.3 & 78.6 & 68.7 \\
\hline & $+2.8-4$ & 86.5 & 91.1 & 91.5 & 87.1 & 78.0 \\
\hline & $+4-5.6$ & 90.6 & 89.2 & 89.0 & 90.4 & 79.6 \\
\hline
\end{tabular}


Table 5. Influence of the particle size in the recovery and grade of the non-floated (concentrated of PVC-M) and floated products, in the separation of bi-component mixtures in the presence of sodium lignosulfonate.

\begin{tabular}{|c|c|c|c|c|c|c|}
\hline & \multirow{3}{*}{$\begin{array}{l}\text { Size fraction } \\
(\mathbf{m m})\end{array}$} & \multicolumn{2}{|c|}{ Non-Floated } & \multicolumn{2}{|c|}{ Floated } & \multirow{2}{*}{$\begin{array}{c}\text { Separation } \\
\text { efficiency }\end{array}$} \\
\hline & & PVC-M & PVC-M & PS & PS & \\
\hline & & Recovery (\%) & Grade (\%) & Recovery (\%) & Grade (\%) & $(\mathrm{SE})(\%)$ \\
\hline \multirow[t]{7}{*}{ PVC-M/PS } & $+1-1.4$ & 39.7 & 98.0 & 99.2 & 62.2 & 38.9 \\
\hline & $+1.4-2$ & 62.6 & 97.5 & 98.4 & 72.4 & 61.0 \\
\hline & $+2-/ 2.8$ & 87.3 & 90.9 & 91.3 & 87.8 & 78.6 \\
\hline & $+2.8-4$ & 97.8 & 78.6 & 73.4 & 97.1 & 71.2 \\
\hline & $+4-5.6$ & 99.5 & 65.0 & 46.3 & 98.9 & 45.8 \\
\hline & & PVC-M & PVC-M & PMMA & PMMA & \multirow{2}{*}{ SE $(\%)$} \\
\hline & & Recovery (\%) & Grade (\%) & Recovery (\%) & Grade (\%) & \\
\hline \multirow[t]{7}{*}{ PVC-M/PMMA } & $+1-1.4$ & 88.9 & 100.0 & 100.0 & 90.0 & 88.9 \\
\hline & $+1.4-2$ & 96.9 & 99.6 & 99.6 & 97.0 & 96.5 \\
\hline & $+2-/ 2.8$ & 99.8 & 91.9 & 91.2 & 99.8 & 91.0 \\
\hline & $+2.8-4$ & 100.0 & 71.1 & 59.4 & 100.0 & 59.4 \\
\hline & $+4-5.6$ & 100.0 & 56.0 & 21.3 & 100.0 & 21.3 \\
\hline & & PVC-M & PVC-M & PET-S & PET-S & \multirow{2}{*}{ SE $(\%)$} \\
\hline & & Recovery (\%) & Grade (\%) & Recovery (\%) & Grade (\%) & \\
\hline \multirow[t]{7}{*}{ PVC-M/PET-S } & $+1-1.4$ & 90.2 & 86.0 & 85.3 & 89.7 & 75.5 \\
\hline & $+1.4-2$ & 97.8 & 78.5 & 73.2 & 97.1 & 71.0 \\
\hline & $+2-/ 2.8$ & 100.0 & 71.0 & 59.2 & 100.0 & 59.2 \\
\hline & $+2.8-4$ & 100.0 & 66.9 & 50.4 & 100.0 & 50.4 \\
\hline & $+4-5.6$ & 100.0 & 64.7 & 45.4 & 100.0 & 45.4 \\
\hline & & PVC-M & PVC-M & PET-D & PET-D & \multirow{2}{*}{ SE $(\%)$} \\
\hline & & Recovery (\%) & Grade (\%) & Recovery (\%) & Grade (\%) & \\
\hline \multirow[t]{5}{*}{ PVC-M/PET-D } & $+1-1.4$ & 89.3 & 81.2 & 79.4 & 88.1 & 68.7 \\
\hline & $+1.4-2$ & 95.5 & 79.4 & 75.2 & 94.3 & 70.7 \\
\hline & $+2-/ 2.8$ & 100.0 & 77.6 & 71.1 & 100.0 & 71.1 \\
\hline & $+2.8-4$ & 100.0 & 76.9 & 69.9 & 100.0 & 69.9 \\
\hline & $+4-5.6$ & 100.0 & 75.8 & 68.0 & 100.0 & 68.0 \\
\hline
\end{tabular}

mixtures (PVC-M/PMMA $<$ PVC-M/PET-S $\approx$ PVC-M/PET-D $<$ PVC-M/PS) is similar to the order of the bubble-particle aggregates density (PS $<$ PET-D, $<$ PET-S $<$ PMMA $\approx$ PVC-M).

In the presence of sodium lignosulfonate, for the finer fraction, the separation efficiency order of the four plastic mixtures (PVC-M/PS $<$ PVC-M/PET-D $\approx$ PVC-M/ PET-S $<$ PVC-M/PMMA) is similar to the contact angle order (PVC-M $<$ PS $<$ PET-D $<$ PET-S $<$ PMMA). For the coarser fraction, the separation efficiency order of the four plastic mixtures (PVC-M/PMMA $<$ PVC-M/PET-S $\approx$ $\mathrm{PVC}-\mathrm{M} / \mathrm{PS}<\mathrm{PVC}-\mathrm{M} / \mathrm{PET}-\mathrm{D})$ is similar to the order of the bubble-particle aggregates density (PS $<$ PET-D, $<$ PET-S $<$ PMMA $\approx$ PVC-M).

So, in the presence of saponin or sodium lignosulfonate, for the fine particles, the separation is mainly influenced by hydrophobicity difference, and for the coarse particles, the flotation is mainly influenced by the bubble-particle aggregates density and to a lesser extent by the hydrophobicity difference.

\section{Conclusions}

The six plastics are naturally floatable in the absence of a wetting agent. Thus, to separate plastic mixtures by froth flotation, saponin and sodium lignosulfonate have been tested to render one component of the mixture more hydrophilic. Contact angle and floatability of the six plastics decreased with the increase of the saponin and sodium lignosulfonate concentration.

In the presence of the two agents, plastic floatability is not only dominated by hydrophobicity/wettability but also by particle weight (size, shape and density). Flotation recovery decreased with the increase of the particle size, an influence that was more noted in the plastics with more spherical shapes (PMMA and PVC-D). For fine particles, the floatability was mainly influenced by the hydrophobicity, and for coarse particles the floatability was strongly influenced by the weight of the particles.

In the presence of saponin or sodium lignosulfonate, PVC-M is the plastic with lower floatability. For separation of the PVC-M mixture with PS, saponin led to better results than sodium lignosulfonate, but for separation of PVC-M mixture with the other three plastics, sodium lignosulfonate led to better results than saponin. The best results were obtained in the PVC-M/PMMA mixture with sodium lignosulfonate, having the highest separation efficiency (71.4\%). For the $+1.4-2 \mathrm{~mm}$ fraction the separation efficiency was the maximum (96.5\%).

Separation efficiency of plastic mixtures changes according to the mixture and also depends on the size, shape and density of the particles. Separation quality improves when the most hydrophobic plastic has lower density, lamellar shape and smaller size. 


\section{Acknowledgements}

This work was supported by the Portuguese Foundation for Science and Technology (FCT-MEC) through national funds and, when applicable, co-financed by FEDER in the ambit of the partnership PT2020, through the following research projects: UID/Multi/00073/2013 of the Geosciences Center of the University of Coimbra.

\section{References}

1. PlasticsEurope. (2018). Plastics - the facts 2017: an analysis of european plastics production, demand and waste data. Brussels. Retrieved in 2018 June 15, from http://www.plasticseurope. org/en/resources/publications/plastics-facts-2017

2. Shent, H., Pugh, R. J., \& Forssberg, E. (1999). A review of plastics recycling and the flotation of plastics. Resources, Conservation and Recycling, 25(2), 85-109. http://dx.doi. org/10.1016/S0921-3449(98)00017-2.

3. Fraunholcz, N. (2004). Separation of waste plastics by froth flotation, review, part I. Minerals Engineering, 17(2), 261-268. http://dx.doi.org/10.1016/j.mineng.2003.10.028.

4. Wang, C. Q., Wang, H., Fu, J. G., \& Liu, Y. N. (2015a). Flotation separation of waste plastics for recycling - A review. Waste Management, 41, 28-38. http://dx.doi.org/10.1016/j. wasman.2015.03.027. PMid:25869841.

5. Singh, N., Hui, D., Singh, R., Ahuja, I. P. S., Feo, L., \& Fraternali, F. (2017). Recycling of plastic solid waste: a state of art review and future applications. Composites. Part B, Engineering, 115, 409-422. http://dx.doi.org/10.1016/j.compositesb.2016.09.013.

6. Shibata, J., Matsumoto, S., Yamamoto, H., Kusaka, E., \& Pradip, P. (1996). Flotation separation of plastics using selective depressants. International Journal of Mineral Processing, 48(3-4), 127-134. http://dx.doi.org/10.1016/S0301-7516(96)00021-X.

7. Marques, G. A., \& Tenório, J. A. S. (2000). Use of froth flotation to separate PVC/PET mixtures. Waste Management (New York, N.Y.), 20(4), 265-269. http://dx.doi.org/10.1016/ S0956-053X(99)00333-5.

8. Shen, H., Forssberg, E., \& Pugh, R. J. (2002). Selective flotation separation of plastics by chemical conditioning with methyl cellulose. Resources, Conservation and Recycling, 35(4), 229-241. http://dx.doi.org/10.1016/S0921-3449(02)00003-4.

9. Alter, H. (2005). The recovery of plastics from waste with reference to froth flotation. Resources, Conservation and Recycling, 43(2), 119-132. http://dx.doi.org/10.1016/j. resconrec.2004.05.003.

10. Takoungsakdakun, T., \& Pongstabodee, S. (2007). Separation of mixed post-consumer PET-POM-PVC plastic waste using selective flotation. Separation and Purification Technology, 54(2), 248-252. http://dx.doi.org/10.1016/j.seppur.2006.09.011.

11. Kangal, M. O. (2010). Selective flotation technique for separation of PET and HDPE used in drinking water bottles. Mineral Processing and Extractive Metallurgy Review, 31(4), 214-223. http://dx.doi.org/10.1080/08827508.2010.483362.

12. Carvalho, M. T., Ferreira, C., Santos, L. R., \& Paiva, M. C. (2012). Optimization of froth flotation procedure for poly (ethylene terephthalate) recycling industry. Polymer Engineering and Science, 52(1), 157-164. http://dx.doi.org/10.1002/pen.22058.

13. Wang, H., Chen, X. L., Bai, Y., Guo, C., \& Zhang, L. (2012). Application of dissolved air flotation on separation of waste plastics ABS and PS. Waste Management, 32(7), 1297-1305. http://dx.doi.org/10.1016/j.wasman.2012.03.021. PMid:22503154.

14. Yenial, U., Kangal, O., \& Güney, A. (2013). Selective flotation of PVC using gelatin and lignin alkali. Waste Management \& Research, 31(6), 613-617. http://dx.doi. org/10.1177/0734242X13476748. PMid:23439876.

15. Saisinchai, S. (2014). Separation of PVC from PET/PVC mixtures using flotation by calcium lignosulfonate depressant.
Engineering Journal, 18(1), 45-53. http://dx.doi.org/10.4186/ ej.2014.18.1.45.

16. Güney, A., Özdilek, C., Kangal, O., \& Burat, F. (2015). Flotation characterization of PET and PVC in the presence of different plasticizers. Separation and Purification Technology, 151, 47-56. http://dx.doi.org/10.1016/j.seppur.2015.07.027.

17. Negari, M. S., Movahed, S. O., \& Ahmadpour, A. (2018). Separation of polyvinylchloride (PVC), polystyrene (PS) and polyethylene terephthalate (PET) granules using various chemical agents by flotation technique. Separation and Purification Technology, 194, 368-376. http://dx.doi. org/10.1016/j.seppur.2017.11.062.

18. Pascoe, R. D., \& Hou, Y. Y. (1999). Investigation of the importance of particle shape and surface wettability on the separation of plastics in a LARCOMEDS separator. Minerals Engineering, 12(4), 423-431. http://dx.doi.org/10.1016/S08926875(99)00022-9.

19. Shen, H., Forssberg, E., \& Pugh, R. J. (2001). Selective flotation separation of plastics by particle control. Resources, Conservation and Recycling, 33(1), 37-50. http://dx.doi. org/10.1016/S0921-3449(01)00056-8.

20. Burat, F., Güney, A., \& Kangal, M. O. (2009). Selective separation of virgin and post-consumer polymers (PET and PVC) by flotation method. Waste Management, 29(6), 1807-1813. http://dx.doi.org/10.1016/j.wasman.2008.12.018. PMid:19155169.

21. Wang, C. Q., Wang, H., \& Liu, Y. N. (2015). Separation of polyethylene terephthalate from municipal waste plastics by froth flotation for recycling industry. Waste Management, 35, 42-47. http://dx.doi.org/10.1016/j.wasman.2014.09.025. PMid:25449606.

22. Pita, F., \& Castilho, A. (2017). Separation of plastics by froth flotation. The role of size, shape and density of the particles. Waste Management, 60, 91-99. http://dx.doi.org/10.1016/j. wasman.2016.07.041. PMid:27478025.

23. Schulz, N. F. (1970). Separation efficiency. In Transactions of The 247 ${ }^{\circ}$ SME (pp. 81-87). Englewood: AIME.

24. Basarová, P., Bartovská, L., Korínek, K., \& Horn, D. (2005). The influence of flotation agent concentration on the wettability and flotability of polystyrene. Journal of Colloid and Interface Science, 286(1), 333-338. http://dx.doi.org/10.1016/j. jcis.2005.01.016. PMid:15848435.

25. Ma, N. (2008). Direct force measurements between surfaces coated with hydrophobic polymers in aqueous solutions and the separation of mixed plastics by flotation (Master's dissertation). Faculty of the Virginia, Blacksburg, Virginia.

26. Pongstabodee, S., Kunachitpimol, B., \& Damronglerd, S. (2008). Combination of three-stage sink-float method and selective flotation technique for separation of mixed post-consumer plastic waste. Waste Management, 28(3), 475-483. http:// dx.doi.org/10.1016/j.wasman.2007.03.005. PMid:17493796.

27. Abbasi, A., Salarirad, M. M., \& Ghasemi, I. (2010). Selective Separation of PVC from PET/PVC Mixture Using Floatation by Tannic Acid Depressant. Iranian Polymer Journal, 19(7), 483-489.

28. Wang, H., Wang, C. Q., Fu, J. G., \& Gu, G. H. (2014). Flotability and flotation separation of polymer materials modulated by wetting agents. Waste Management, 34(2), 309-315. http:// dx.doi.org/10.1016/j.wasman.2013.11.007. PMid:24355830.

29. Florido, P. L., \& Torem, M. L. (2001). Selective flotation of polyvinyl chloride (PVC/polyethylene terephthalate (PET) mixtures. In Proceedings oh The VI Southern Hemisphere Meeting on Mineral Technology (pp. 708-713). Rio de Janeiro: Corbã Editora Artes Gráficas. 